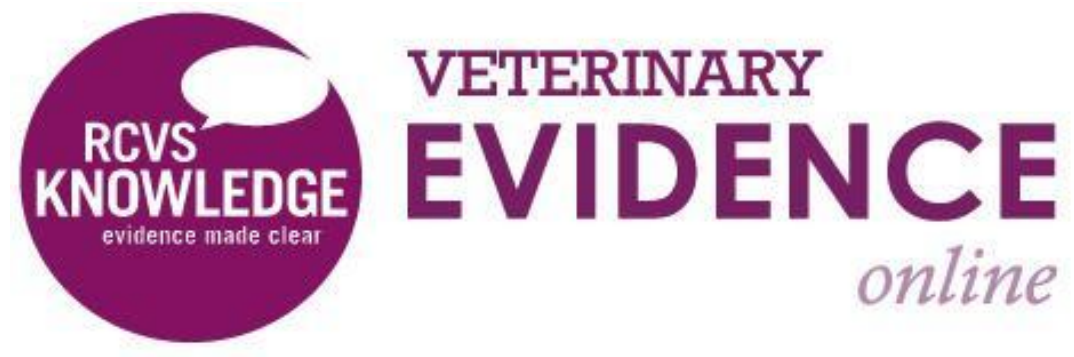

\title{
Does Physical Therapy after a TPLO Lead to Improvement of the 1-Year Post-Operative Peak Vertical Force?
}

A Knowledge Summary by

Andrea Faure Beaulieu BVSc ${ }^{1 *}$

Antonio Pozzi DMV ${ }^{1}$

\footnotetext{
${ }^{1}$ Vetsuisse Faculty, University of Zurich, Rämistrasse 71, 8006 Zürich, Switzerland

* Corresponding Author (andrea.fb@hotmail.ch)
}

ISSN: 2396-9776

Published: 21 Sep 2016

in: Vol 1, Issue 3

DOI: http://dx.doi.org/10.18849/ve.v1i3.31

Reviewed by: Adam Swallow (BVSc MRCVS) 


\section{KNOWLEDGE SUMMARY}

\section{Clinical bottom line}

Based on the lack of sufficient clinical studies investigating the PICO question, it is not possible to conclude if physical therapy should be recommended as a routine postoperative treatment after TPLO.

\section{Question}

Does postoperative rehabilitation improve 1-year postoperative peak vertical force (PVF) after a tibial plateau levelling osteotomy (TPLO) in dogs?

\section{The evidence}

A dog needs to undergo a TPLO as a result of a ruptured cranial cruciate ligament. The owner, an ambitious footballer, coincidentally had to operate his knee two years ago for the same reason. He would like to know if the postoperative rehabilitation is comparable and if there is any evidence that physical therapy in dogs provides similar benefits as in humans (van Melick 2016).

\section{Summary of the evidence}

\begin{tabular}{|c|c|}
\hline \multicolumn{2}{|l|}{ Wucherer (2013) } \\
\hline Population: & $\begin{array}{l}\text { Overweight dogs with unilateral cranial cruciate ligament rupture } \\
\text { (CCLR) }\end{array}$ \\
\hline Sample size: & 40 dogs $n=40$ \\
\hline Intervention details: & $\begin{array}{l}\text { Two treatment groups: } \\
n=19 \text { nonsurgical treatment group (physical therapy, weight loss, } \\
\text { and Non-steroidal anti-inflammatory drugs [NSAID] administration) } \\
n=21 \text { surgical treatment group (TPLO + nonsurgical treatment) }\end{array}$ \\
\hline Study design: & Randomised controlled trial \\
\hline Outcome studied: & $\begin{array}{l}\text { Subjective: } \\
\text { Owners had to complete questionnaires (canine brief pain inventory } \\
\text { [CBPI] and VAS [visual analogue scale]) at each outcome measure } \\
\text { time. } \\
\text { Objective: } \\
\text { Functional and clinical scores (peak vertical force [PVF], vertical } \\
\text { impulse [VI], body weight and body fat). }\end{array}$ \\
\hline $\begin{array}{l}\text { Main findings: } \\
\text { (relevant to PICO question): }\end{array}$ & $\begin{array}{l}\text { Dogs with CCLR treated with surgical and nonsurgical interventions } \\
\text { had better outcomes than dogs only with nonsurgical treatment } \\
\text { - significant }(P<0.05) \text { improvements of pain severity and }\end{array}$ \\
\hline
\end{tabular}




\begin{tabular}{|l|l|}
\hline Limitations: & $\begin{array}{c}\text { interference score at the 52-week evaluation of the } \\
\text { questionnaires } \\
\text { significant }(\mathrm{P}<0.05) \text { higher mean PVF at the 24- and 52- } \\
\text { week evaluations }\end{array}$ \\
\hline $\begin{array}{l}\text { AND different surgical procedures (arthroscopy vs. arthrotomy) } \\
\text { veterinary surgeon or a surgical resident under the direct supervision } \\
\text { of a board-certified veterinary surgeon) }\end{array}$ \\
$\begin{array}{l}\text { Due to complications during the time of follow-up (most common } \\
\text { cause was the development of contralateral CCLR) dogs were } \\
\text { successively excluded from the study. Of the initial } 40 \text { dogs only data } \\
\text { of 23 were used at the 52-week evaluation. }\end{array}$ \\
\hline
\end{tabular}

\begin{tabular}{|c|c|}
\hline \multicolumn{2}{|l|}{ Au (2010) } \\
\hline Population: & $\begin{array}{l}\text { Medium to large breed dogs with naturally occurring cranial cruciate } \\
\text { ligament }(\mathrm{CrCL}) \text { injury }\end{array}$ \\
\hline Sample size: & 65 dogs $n=65$ \\
\hline Intervention details: & $\begin{array}{l}\text { Two treatment groups with different surgical interventions and the } \\
\text { same postoperative physical rehabilitation: } \\
n=35 \text { had lateral fabellar suture (LFS) } \\
n=30 \text { had TPLO }\end{array}$ \\
\hline Study design: & Non-randomised controlled trial \\
\hline Outcome studied: & $\begin{array}{l}\text { Objective: } \\
\text { Radiographic osteoarthritis (OA) and functional/clinical scores } \\
\text { (PVF, stifle joint range of motion and thigh circumference) }\end{array}$ \\
\hline $\begin{array}{l}\text { Main findings: } \\
\text { (relevant to PICO question): }\end{array}$ & $\begin{array}{l}\text { Increase of PVF from } 3 \text { weeks to } 24 \text { months but no significant } \\
\text { difference between both groups } \\
\text { - Mean PVF at } 3 \text { weeks evaluation: } \\
\text { - } \text { MFS group ( } 17.57 \pm 70 \text { ) and TPLO group }(20.65 \pm 1.73) \\
\text { Mean PVF at } 24 \text { months evaluation: } \\
\text { Increase of radiographic OA scores from preoperative to } 24 \text { months } \\
\text { in both groups but no significant difference between both groups } \\
\text { (potential OA scores ranged from } 0 \text { to } 63) \text { : } \\
\text { - Radiographic score at preoperative evaluation: } \\
\text { LFS group (18.5 } \pm 59 \text { ) and TPLO group (16.38 } \pm 1.91) \\
\text { Radiographic score at } 24 \text {-month evaluation: } \\
\text { LFS group ( } 28.21 \pm 2.84 \text { ) and TPLO group }(24.31 \pm 2.42)\end{array}$ \\
\hline Limitations: & $\begin{array}{l}\text { - Significant differences between the groups at the start of the } \\
\text { trial: age, weight, breeds and thigh circumference. }\end{array}$ \\
\hline
\end{tabular}




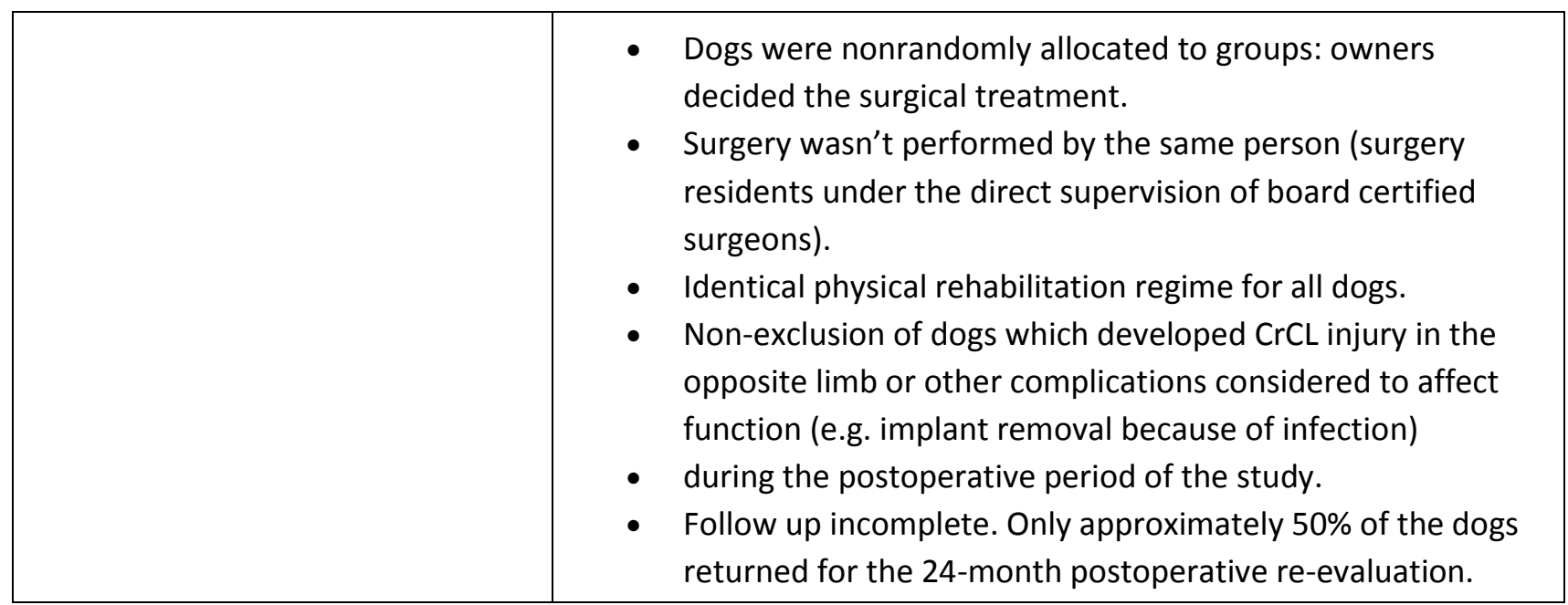

\section{Appraisal, application and reflection}

Only two papers relevant to the PICO were found in the literature analysing the ground reaction force (GRF) over a longer time period of dogs with unilateral CCLR after a TPLO and/or physical therapy.

Wucherer et al. (2013) compared, in a randomised controlled trial, overweight dogs with CCLR which were assigned to a non-surgical (physical therapy, NSAID administration and weight loss) and a surgical (TPLO) + physical therapy treatment group. Both groups received the same non-surgical therapy. The physical therapy, which was conducted by the same person, was individually designed for each dog and included at least 6 supervised sessions over 12 weeks. While the non-surgical treatment group had its first session at the beginning of the trial, the surgical group started 2 weeks after the surgery.

The study was able to show that the mean PVF of the dogs in the surgical treatment group was significantly higher after 24 and 52 weeks after the start of the study, compared with the non-surgical treatment group.

In the nonrandomised controlled trial from Au et al. (2010) dogs with CCLR underwent either a TPLO or a LFS as surgical intervention. Both groups were followed by an identical physical rehabilitation regime performed by the same experienced handler. Even if the PVF scores were recorded during 2 years on a regular basis no significant differences between the two groups could be shown. This work has some bias since the two groups were not similar (different age, weight, breeds), the follow up was incomplete and the dogs having developed $\mathrm{CrCL}$ injury on the opposite limb or other complications during the study period, were kept in the group. Moreover, the surgeries in both studies were done by different surgeons and were not conducted identically. This will additionally compromise the strength of the results.

In conclusion, there is currently insufficient evidence to prove the benefit of postoperative physical therapy after a TPLO based on an increase in PVF at 1 year recheck follow-up. However, there is some preliminary evidence that rehabilitation may be beneficial for the postoperative period, although further studies are needed. To provide evidence that rehabilitation should be included as routine postoperative treatment after TPLO, a prospective, randomised study should be performed. Dogs should undergo TPLO and rehabilitation by the same individuals following consistent protocols to reduce variability. Dogs should be followed for at least 1 year after surgery. 


\section{Methodology Section}

\begin{tabular}{|r|l|}
\multicolumn{1}{|l}{ Search Strategy } \\
$\begin{aligned} \text { Databases searched and dates } \\
\text { covered: }\end{aligned}$ & $\begin{array}{l}\text { CAB Abstracts on the CAB Direct interface, date range: } 1973 \text { - } 2016 \\
\text { and PubMed accessed via the NCBI interface, date range: } 1971 \text { - } \\
2016\end{array}$ \\
\hline Search terms: & $\begin{array}{l}\text { ( dog OR dogs OR canine OR canines OR canis OR puppy OR puppies } \\
\text { ) AND (TPLO OR "tibial plateau leveling osteotomy" OR "tibial } \\
\text { plateau levelling osteotomy" OR "tibial plateau leveling" OR "tibial } \\
\text { plateau levelling") AND ("vertical force" OR "ground reaction force" } \\
\text { OR GRF OR "force plate" OR "pressure platform" OR plate OR } \\
\text { platform OR compression OR force OR pressure) }\end{array}$ \\
\hline Dates searches performed: & \begin{tabular}{l} 
December 7th 2015 \\
\hline
\end{tabular} \\
\hline
\end{tabular}

\section{Exclusion / Inclusion Criteria}

Exclusion: Non English language, non-systematic review, conference papers or summary updates.

Inclusion: Studies which include rehabilitation, TPLO and GRF at the same time.

\section{Search Outcome}

\begin{tabular}{|l|c|c|c|c|}
\hline \multicolumn{1}{|c|}{ Database } & Number of results & $\begin{array}{c}\text { Excluded - non- } \\
\text { English language } \\
\text { publication }\end{array}$ & $\begin{array}{c}\text { Excluded - as didn't } \\
\text { include the criteria } \\
\text { rehabilitation, TPLO and } \\
\text { GRF at the same time }\end{array}$ & $\begin{array}{c}\text { Total relevant } \\
\text { papers }\end{array}$ \\
\hline CAB Abstracts & 80 & 11 & 67 & 2 \\
\hline NCBI PubMed & 66 & 0 & 65 & 1 \\
\hline Total relevant papers when duplicates removed
\end{tabular}




\section{CONFLICT OF INTEREST}

The authors declare no conflicts of interest.

\section{REFERENCES}

1. van Melick, N. et al. (2016) Evidence-Based Clinical Practice Update: Practice Guidelines for Anterior Cruciate Ligament Rehabilitation Based on a Systematic Review and Multidisciplinary Consensus. British Journal of Sports Medicine, [in process] http://dx.doi.org/10.1136/bjsports-2015$\underline{095898}$

2. Wucherer, K. L. et al. (2013) Short-Term and Long-Term Outcomes for Overweight Dogs with Cranial Cruciate Ligament Rupture Treated Surgically or Nonsurgically. Journal of the American Veterinary Medical Association, 242 (10), pp. 136- 472. http://dx.doi.org/10.2460/javma.242.10.1364

3. Au, K. K. et al. (2010) Comparison of Short and LongTerm Function and Radiographic Osteoarthrosis in Dogs after Postoperative Physical Rehabilitation and Tibial Plateau Leveling Osteotomy or Lateral Fabellar Suture Stabilization. Veterinary Surgery, 39 (2), pp. 173-180. http://dx.doi.org/10.1111/j.1532$\underline{950 X .2009 .00628 . x}$ 


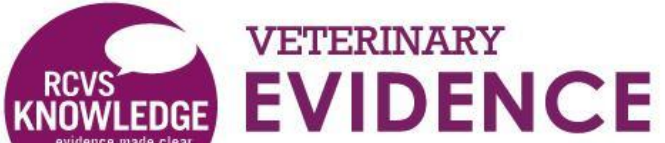 \\ orthe}

\section{Intellectual Property Rights}

Authors of Knowledge Summaries submitted to RCVS Knowledge for publication will retain copyright in their work, but will be required to grant to RCVS Knowledge an exclusive license of the rights of copyright in the materials including but not limited to the right to publish, re-publish, transmit, sell, distribute and otherwise use the materials in all languages and all media throughout the world, and to license or permit others to do so.

Authors will be required to complete a license for publication form, and will in return retain certain rights as detailed on the form.

Veterinary Evidence and EBVM Network are RCVS Knowledge initiatives. For more information please contact us at editor@veterinaryevidence.org.

RCVS Knowledge is the independent charity associated with the Royal College of Veterinary Surgeons (RCVS). Our ambition is to become a global intermediary for evidence based veterinary knowledge by providing access to information that is of immediate value to practicing veterinary professionals and directly contributes to evidence based clinical decision-making.

\section{www.veterinaryevidence.org}

RCVS Knowledge is a registered Charity No. 230886. Registered as a Company limited by guarantee in England and Wales No. 598443.

Registered Office:

Belgravia House

62-64 Horseferry Road

London SW1P 2AF 